Jurnal Pendidikan dan Pembelajaran Dasar

p ISSN: 1979-5599 | e ISSN: 2502-194X

Pag e

\title{
UPAYA MENINGKATKAN KEMAMPUAN GURU DALAM MEMAHAMI \\ KONSEP MEDIA PEMBELAJARAN DAN KETERAMPILAN GURU PKN \\ DALAM MENGGUNAKAN MEDIA PEMBELAJARAN (IN FOCUS) \\ MELALUI METODE PELATIHAN IN-SERVICE-TRAINING DI GUGUS IV KECAMATAN SUKARAJA KABUPATEN BOGOR
}

\author{
Encep Burhanudin \\ Postgraduate Sekolah Tinggi Keguruan dan Ilmu Pendidikan Arrahmaniyah Depok \\ encep.burhanudin@gmail.com
}

\begin{abstract}
This research aims to know the capacity of teachers in understanding learning media and concepts of learning and skills teachers PKN in using media learning through in-service training methods-training. The method of research used the qualitative Research with engineering support (Research Action class). The results of this research are as follows: Inservice Training Training Implementation can improve the understanding of teachers about Media Pemebelajaran in cluster IV sub district of Bogor regency Well-known; Application of Training In Service Training can improve the skills of teachers in using media learning in Cluster IV sub district of Bogor regency Well-known. Application of inservice training training together can improve the understanding of teachers PKn about media learning and skills teachers PKn in learning to use media (in focus) in Cluster IV Sub Well-known Bogor regency.
\end{abstract}

Keyword: Learning; Media Skills; Teacher in-Service-Training Copyright (C) 2017 Madrasah Jurnal Pendidikan dan Pembelajaran Dasar. All Right Reserved

\section{A. PENDAHULUAN}

Sumber daya manusia memegang penanan yang krusial guna berkembangnya suatu bangsa, untuk itu perlu upaya yang mampu mempersiapkan sumber daya manusa untuk dapat memiliki kualitas yang baik. Terlebih lagi dalam era MEA masyarakat di tuntut untuk dapat menjadi masyarakat yang cerdas damai terbuka dan demokratis, agar dapat bersaing dalam kancah internasional pasca di terapkanya kebijakan MEA. Dalam hal ini pendidikan dapat mengambil peran strategis guna mempersiapkan dan meningkatkan kualitas sumber daya manusia. Untuk dapat memerankan peranya secara optimal pendidikan acap kali di tuntut untuk melakukan pembaharuan agar dapat meningkatkan kulaitiasnya, harapanya dengan pendidikan yang berkualitas dapat menciptakan SDM yang berkualitas dan hal itu dapat memajukan bangsa Indonesia.

Telah ada berbagai macam upaya yang dilakukan untuk meningkatkan kualitas pendidikan yang ada di Indonesia, salah satunya terkait dengan peningkatan kualitas kegiatan belajar mengajar. Beberapa upaya guna mengingkatkan kegiatan belajar mengajar tersebut seperti :

1. Pembaharuan dan pengembangan pada kurikulum

2. Pembaharuan dan engembangan model dan media pembelajaran

3. Pengembangan dan pembaharuan sistem penilaian hasil belajar

Dari beberapa upaya tersebut media pembelajaran menjadi salah satu faktor yang berperan penting dalam menentukan keberhasilan pembelajaran yakni media

Vol. 10 No. 1, Desember 2017

Madrasah homepage: http://ejournal.uin-malang.ac.id/index.php/madrasah/index 
pembelajaran. Media pembelajaran dapat secara efektif meningkatkan kualitas proses pembelajaran yang dilakukan oleh guru. Dengan menggunakan media pemebeljaran yang efektif dan interaktif khususnya di Sekolah Dasar, pembelajaran dapat dilakukan dengan menyenangkan serta dapat menarik minat dan perhatian serta keaktifan siswa dalam mengikuti pembelajaran. Selama ini dari observasi yang dilakukan di gugus IV Kecamatan Sukaraja Kabupaten Bogor 85\% guru tidak menggunakan media pembelajaran dalam Kegiatan Belajar Mengajar. Keaktifan menjadi suatu perhatian yang utama dalam pembelajaran pelajaran PPKn, karena pada dasarnya mata pelajaran ini memberikan bekal pada siswa untuk dapat berpartisipasi aktif dalam masyarakat (Feriandi, 2016).

Untuk itu guru perlu meningkatkan kemampuan untuk dapat menggunakan media pembelajaran agar mampu meningkatkan keaktifan siswa dalam pembelajaran khususnya mata pelajaran PKn. Karena pada dasarnya seorang guru harus dapat mengambil suatu tindakan untuk mengatasi masalah-masalah atau kejadian yang ada dalam kelas. Implikasinya yakni guru harus dapat mengembangkan media agar mampu meningkatkan kemampuan siswa untuk aktif dalam pembelajaran (Moh Uzer Usman, 1999).

Kemampuan guru dalam menggunakan media pembelajaran sangat menunjang akan keberhasilan pembelajaran dikelas. Mengingat selama ini guru kurang trampil dalam menggunakan media tersebut bahkan cenderung tidak mau menggunakan media pembelajaran dalam setiap kegiatan pembelajaran di kelas, padahal dengan media pembelajaran siswa akan lebih termotivasi dalam belajar, dengan media yang bervariasi siswa akan bergairah dalam belajarnya, siswa akan lebih aktif, dan situasi belajar mengajar akan lebih hidup. Hal itu sesuai dengan apa yang di kemukakan Depdikbud (1994) bahwasanya guru merupakan pihak yang mampu untuk mengarahkan dan mendayagunakan faktor-faktor lainya untuk menciptakan proses pembelajaran yang bermutu. Sehingga dapat di katakan bahwa guru merupakan salah satu faktor yang paling menentukan kualitas pembelajaran (Mulyoto\& Feriandi, 2017).

Dari hal tersebut maka dapat di simpulkan bahwa guru merupakan ujung tombak dalam kegiatan belajar mengajar, guru dapat memaksimalkan peranya dalam menggunakan dan mengembangkan media pembelajaran. Harapnya guru dapat menciptakan pembelajaran yang demokratis yang mengedepankan keaktifan siswa. Kondisi pembelajaran di sekolah-sekolah pada umumnya masih bersifat seadanya, para guru menurut pengamatan penulis dalam melaksanakan kegiatan belajar mengajar masih enggan menggunakan media pelajaran, padahal guru sangat menentukan keberhasilan proses pembelajaran, guru harus mendesain pembelajaran dengan skenario yang menarik minat siswa untuk aktif di kelas, untuk itu setelah melakukan pra penelitian ditarik kesimpulan bahwa 85\% guru di wilayah gugus IV Kecamatan Sukaraja Kabupaten Bogor tidak menggunakan media pembelajaran dalam Kegiatan Belajar Mengajar. Sehingga penulis mencoba meneliti permasalahan tersebut dengan judul "Upaya meningkatkan kemampuan guru dalam memahami media pembelajaran dan keterampilan guru Pkn dalam menggunakan media pembelajaran (In focus) melalui model pelatihan in-service training di gugus IV Kecamatan Sukaraja Kabupaten Bogor

\section{Pemahaman Tentang Konsep Media Pembelajaran.}

Dalam segala aspek kehidupan manusia tidak akan terlepas dari pengetahuan, manusia berupaya untuk menambah wawasan pengetahuan mereka dengan berupaya mencari, baik melalui tafakur, tadabbur dan tabyyun dengan media al-quran manusia

Vol. 10 No. 1, Desember 2017

Madrasah homepage: http://ejournal.uin-malang.ac.id/index.php/madrasah/index 


\section{MADRASAH}

Jurnal Pendidikan dan Pembelajaran Dasar

p ISSN: 1979-5599 | e ISSN: 2502-194X

berupaya meningkatkan derajatnya dengan meningkatkan ilmu pengetahuan yang dimilikinya sesuai dengan firman Allah Swt dalam Surat at-Thalaq ayat 12:

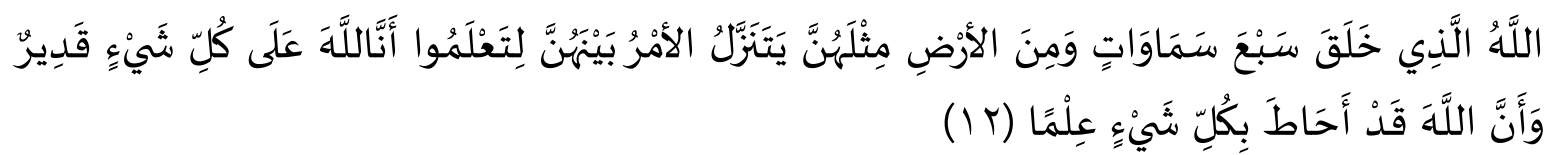

Artinya: "Allah-lah yang menciptakan tujuh langit dan seperti itu pula bumi. perintah Allah Berlaku padanya, agar kamu mengetahui bahwasanya Allah Maha Kuasa atas segala sesuatu, dan Sesungguhnya Allah ilmu-Nya benar-benar meliputi segala sesuatu".

Dengan semakin meningkat dan bertambahnya pengetahuan manusia maka ia akan menjadi manusia yang memiliki ciri khas sesuai dengan disiplin ilmu yang dimilikinya.

\section{Media Pembelajaran.}

Untuk menjadi seorang guru yang baik atau profesional, guru harus mampu mengunakan media pebelajaran dengan baik dan kreatif, sehingga pembelajaran yang dilakukan di kelas. Media pembelajaran dapat di pahami sebagai segala sesuatu yang dapat menyalurkan dan menyampaikan informasi yang berasal dari guru kepada penerima yakni siswa secara efektif dan efisien (Munadi, 2013:8). Mengenai bentuk media pembelajaran dapat berupa media audio, media visual, dan multimedia. Mendukung apa yang di katakan Mudadi, Schramm (dalam ngalim purwanto, 2014), mengatakan bahwa media dapat digolongkan menjadi pada kemampuan daya liputanya. Sehingga secara garis besar media di bagi menjadi 3 bagian (1) media dengan kemampuan liputan luas dan serentak, dalam hal ini contoh medianya seperti Internet, Televisi, radio, surat kabar. (2) media dengan kamampuan liputan terbatas pada ruangan, contoh media ini seperti Film, Power Poin, Video (film, slide, video, foster audio tape, (3) Yang terakir yakni media yang digunakan secara individual, contoh media ini seperti modul, buku pelajaran, dll.

Dengan banyaknya pilihan media yang bisa di gunakan, guru memiliki keleluasaan untuk memilih dan mengembangkan media sesuai dengan kebutuhan yang di miliki, dalam memilih guru media hendanya guru mempertimbangkan berbagai hal termasuk salah satunya adalah materi pembelajaranya serta karakteristik siswa yang di ajar. Hal itu sesuai dengan apa yang dikatakan oleh Allen (Dalam Ngalim Purwanto, 2014) bahwa terkadang suatu media memiliki kecocokan dengan materi atau tujuan pembelajaran tertentu, namun tidak cocok untuk digunakan dengan materi yang lain.

Berdasarkan pemahaman atas klarifikasi media pembelajaran tersebut, akan dipermudah para guru atau praktisi lainnya dalam melakukan pemilihan media yang tepat pada waktu merencanakan pembelajaran untuk mencapai tujuan tertentu. Pemilihan media yang disesuaikan dengan tujuan, materi serta kemampuan dan karakteristik pembelajar akan sangat menunjang efisiensi dan efektivitas proses dan hasil pembelajaran.

Vol. 10 No. 1, Desember 2017

Madrasah homepage: http://ejournal.uin-malang.ac.id/index.php/madrasah/index 


\section{Pelatihan In Service Training}

Pelatihan In Service Trainig merupakan usaha pelatihan yang memberi kesempatan kepada guru dalam rangka meningkatkan kinerja guru. Berikut ini adalah program dari pelatihan in service training adalah Kegiatan Kelompok Kerja Guru (KKG), Musyawarah Guru Mata Pelajaran (MGMP), Musyawarah kerja Kepala Sekolah (MKKS).

Menurut beberapa tokoh mengemukakan bahwa pelatihan merupakan suatu proses yang bertujuan untuk meningkatkan keterampilan, mengembangkan bakat dan kemampuan seorang guru agar proses pembelajaran lebih berkualitas (Edwin B Filipo; Michael J. 1971;1972).

Kemudian Simamora (1995) mendefinisikan suatu aktifitas yang bertujuan untuk meningkatkan keterampilan, pengalaman atau perubahan dari individu. Kemudian dalam instruksi presiden No. 15 tahun 1974, pelatihan merupakan bagian dari pendidikan yang didalamnya terdiri dari proses belajar yang bertujuan untuk meningkatan keterampilan dengan menggunakan metode yang lebih mengutamakan praktik daripada teori.

Pelatihan sangat berhubungan dengan pendidikan. Karena di dalam pelatihan terdapat unsur pendidikan yang tidak bisa dipisahkan. Berikut ini beberapa kriteria yang dikemukakan oleh Pieters (1996):

a. Pendidikan sebenarnya adalah suatu hal yang bermanfaat bagi mereka yang terlibat di dalamnya.

b. Pendidikan wajib melibatkan pengetahuan dan pemahaman serta sejumlah perspektif kognitif.

c. Pendidikan setidaknya memiliki sejumlah prosedur, dengan asumsi bahwa peserta didik belum memiliki pengetahuan dan kesiapan belajar secara sukarela.

Menurut Undang-Undang system pendidikan Nasional Nomor 20 tahun 2005, dikemukakan bahwa pendidikan adalah usaha sadar dan terencana untuk mewujudkan suasana belajar dan proses pembelajaran abar peserta didik secara aktif mengembangkan potensi dirinya untuk memiliki kekuatan spiritual keagamaan, pengendalian diri, kepribadian, kecerdasan, akhlaq mulia, serta keterampilan yang diperlukan dirinya, masyarakat, bangsa dan negara.

\section{B. PEMBAHASAN}

Hasil observasi pada siklus 1 yang diperoleh peserta pada pelaksanaan perbaikan siklus 1 yang terdapat peserta yang menggunakan media pembelajaran (in focus) diperoleh data sebagai berikut: tidak pernah menggunakan 15 orang atau 55,56\%, jarangan menggunakan 10 orang atau 37,04\%, sering menggunakan 2 orang atau 7,41\% dan yang sering mengunakan 0 orang atau $0 \%$.

Berdasarkan skor yang telah dibuat maka diketahui skor 47 sebesar 3,79\% sebanyak 1 orang. Skor 53 sebesar 3,79 \% sebanyak 1 orang. Skor 57 sebesar 11,11\% sebanyak 3 0rang. skor terbanyak berada pada skor 60 sebesar 25,92\% sebanyak 7 orang dan pada skor 63 sebesar 22,22\% sebanyak 6 orang. Pada skor 67 sebesar 22,22\% sebanyak 6 orang, dan pada skor 67 sebesar $7,41 \%$ sebanyak 2 orang, skor 73 sebesar 3,79 $\%$ sebanyak 1 orang. Dalam kegiatan siklus 1 ini, sebagian nampaknya kemampuan pemahaman dan keterampilan dalam menggunakan media pembelajaran masih kurang dikarenakan masih ada peserta (guru) yang belum menguasai menguasai materi pelatihan. Atas dasar itu penulis melakukan perbaikan pembelajaran, dan melanjutkan penelitian pada siklus 2 .

Vol. 10 No. 1, Desember 2017

Madrasah homepage: http://ejournal.uin-malang.ac.id/index.php/madrasah/index 


\section{MADRASAH}

Jurnal Pendidikan dan Pembelajaran Dasar

p ISSN: 1979-5599 | e ISSN: 2502-194X

Page $\mid 61$

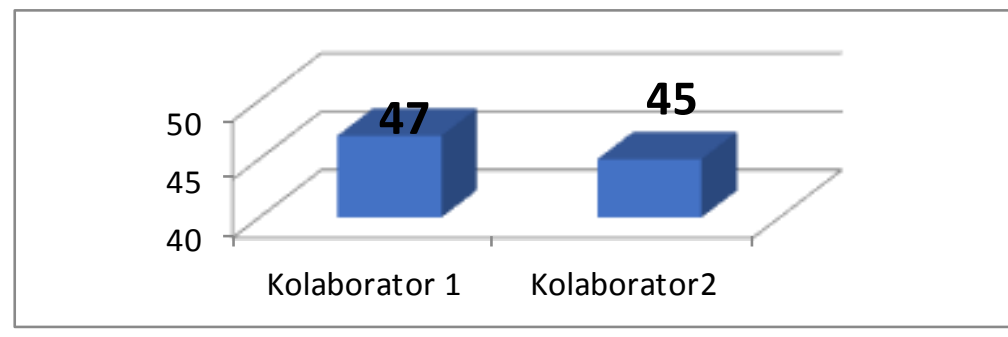

Gambar 1.1. Diagram Histogram Hasil Observasi Keterampilan dalam Menggunakan Media Pembelajaran Siklus I

Hasil observasi pada siklus 2 yang diperoleh peserta pada pelaksanaan perbaikan siklus 2 yang terdapat peserta yang menggunakan media pembelajaran (in focus) diperoleh data sebagai berikut: tidak pernah menggunakan 8 orang atau 29,63\%, pernah menggunakan 11 orang atau 40,74\%, kadang-kadang menggunakan 5 orang atau 18,52\% dan yang selalu mengunakan 3 orang atau $11,11 \%$.

Berdasarkan skor yang telah dibuat maka diketahui skor 63 sebesar 3,70\% sebanyak 1 orang. Skor 67 sebesar 7,40\% sebanyak 2 orang. Skor 70 sebesar 14,81\% sebanyak 4 0rang. Skor 71 sebesar 3,70\% sebanyak 1 orang, skor 72 sebesar 7,40\% sebanyak 2 orang. Skor terbanyak adalah 73 sebesar 22,22\% sebanyak 6 orang, dan pada skor 74 sebesar 3,70\% sebanyak 1 orang, skor 76 sebesar 3,70\% sebanyak 2 orang. Skor 77 sebesar 3,70\% sebanyak 1 orang. Skor 80 sebesar 11,11\% sebanyak 3 orang. Skor 82 sebesar 3,70\% sebanyak 1 orang. Skor 83 sebesar 7,40\% sebanyak 2 orang. Skor 84 sebesar $3,70 \%$ sebanyak 1 orang. Dalam kegiatan siklus 2, sebagian nampaknya kemampuan pemahaman dan keterampilan dalam menggunakan media pembelajaran masih kurang dikarenakan masih ada peserta (guru) yang belum menguasai menguasai materi pelatihan. Atas dasar itu penulis melakukan perbaikan pembelajaran, dan melanjutkan penelitian pada siklus 3 .

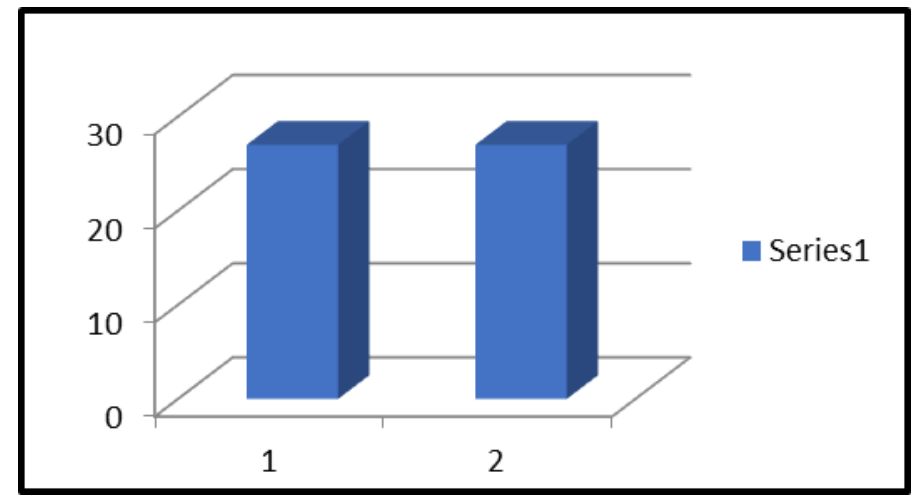

Gambar 1.2. Diagram Histogram Hasil Observasi Keterampilan dalam Menggunkan Media Pembelajaran Siklus 2

Vol. 10 No. 1, Desember 2017

Madrasah homepage: http://ejournal.uin-malang.ac.id/index.php/madrasah/index 
Hasil observasi yang diperoleh peserta pada pelaksanaan perbaikan siklus 3 adalah peserta yang menggunakan media pembelajaran (in focus) diperoleh data sebagai berikut: tidak pernah menggunakan 0 orang atau $0 \%$, jarang menggunakan hanya 2 orang atau $7,41 \%$, sering menggunakan 20 orang atau $74,10 \%$ dan yang selalu mengunakan 5 orang atau $18,52 \%$.

Berdasarkan skor yang telah dibuat maka diketahui skor 65 sebesar 3,70\% sebanyak 1 orang. Skor 70 sebesar 3,70\% sebanyak 1 orang. Skor 72 sebesar 7,40\% sebanyak 2 0rang. Skor 80 sebesar 22,22\% sebanyak 6 orang, skor 85 sebesar 18,51\% sebanyak 5 orang. Skor terbanyak adalah 90 sebesar 25,92\% sebanyak 7 orang, dan pada skor 100 sebesar 18,51\% sebanyak 5 orang.

Dalam kegiatan siklus 3 ini, sebagian nampaknya kemampuan pemahaman dan keterampilan dalam menggunakan media pembelajaran mengalami peningkatan. Atas dasar itu penulis melakukan berhasil melakukan metode In service Training.

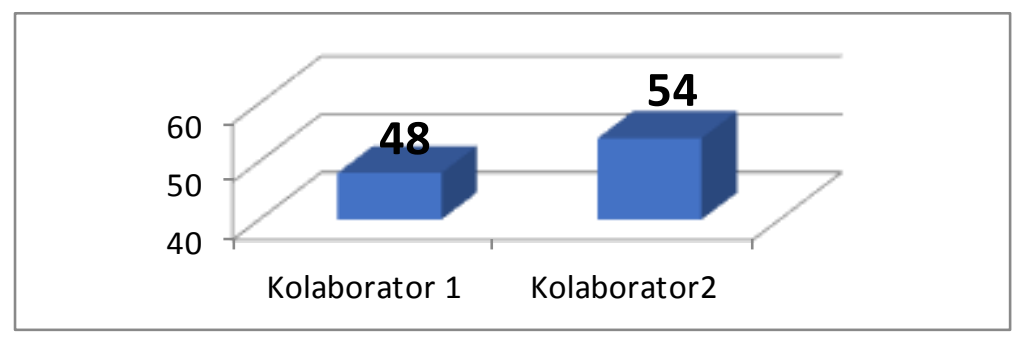

Gambar 1.3. Diagram Histogram Hasil Observasi Keterampilan dalam Menggunkan Media Pembelajaran Siklus 3

Dengan demikian hipotesis yang menyebutkan "Upaya meningkatkan kemampuan guru dalam memahami konsep media pembelajaran dan keterampilan guru PKn dalam menggunakan media pembelajaran (in focus) melalui metode pelatihan inservice di gugus IV Kecamatan Sukaraja dapat diterima dan dinyatakan mengalami peningkatan.

\section{PENUTUP}

Berdasarkan hasil analisis dan pembahasan pada bab sebelumnya, maka peneliti dapat menyimpulkan beberapa hal sehubungan dengan upaya meningkatkan Pemahaman Guru Tentang Media Pemebelajaran dan Keterampilan Guru Menggunakan Media Pembelajaran Melalui Pelatihan Inservice Training sebagai berikut:

1. Penerapan Pelatihan Inservice Training dapat meningkatkan pemahaman Guru Tentang Media Pemebelajaran di Gugus IV Kecamatan Sukaraja Kabupaten Bogor. Ini dibuktikan dari hasil penelitian adanya peningkatan pada tindakan pada setiap siklus. Pada siklus 3 variabel Guru Tentang Media Pemebelajaran, Peserta Pelatihan sudah mencapai kriteria yang ditentukan yaitu 80, yaitu sebanyak sebanyak 27 orang, sedangkan yang mencapai ketuntasan nilai diatas KKM dengan rata-rata 80 dikategorikan baik.

2. Penerapan Pelatihan In Service Training dapat meningkatkan keterampilan guru dalam menggunakan media pembelajaran di gugus IV Kecamatan Sukaraja Kabupaten Bogor. Ini terbukti dar hasil penelitian di siklus 3 dalam variabel keterampilan guru dalam menggunakan media pembelajaran ada peningkatan dari siklus 1 dan 2, dari angket

Vol. 10 No. 1, Desember 2017

Madrasah homepage: http://ejournal.uin-malang.ac.id/index.php/madrasah/index 


\section{MADRASAH}

Jurnal Pendidikan dan Pembelajaran Dasar

p ISSN: 1979-5599 | e ISSN: 2502-194X

P a g e $\mid 63$

skala perilaku ada 20 peserta yang kadang-kadang menggunakan media pembelajaran dan 5 peserta yang selalu menggunakan media pembelajaran.

3. Penerapan pelatihan in service training secara bersama dapat meningkatkan pemahaman guru PKn tentang media pembelajaran dan keterampilan guru PKn dalam menggunakan media pembelajaran (infokus) di gugus IV Kecamatan Sukaraja Kabupaten Bogor. Ini dibuktikan dari hasil pengamatan penelitian, dari segi keaktifan, respon, keberanian dan tanggungjawab peserta dalam mengikuti pelatihan dengan penerapan inservice training, sudah mencapai peningkatan yang signifikan dari pengamatan siklus 1 dan siklus 2 dan rata-rata peningkatan sampai $86 \%$, dan telah melampaui target penelitian sebesar $85 \%$.

\section{REFERENSI}

Abdurrahman, Mulyono. (2009) Pendidikan Bagi Anak Berkesulitan Belajar. Jakarta: Rineka Cipta.

Arikunto, Suharsimi. (2003). Manajemen Pengajaran. Jakarta: Rineka Cipta.

Arikunto, Suharsimi. (2002). Pengelolaan Kelas dan Siswa. Jakarta: Rajawali Press.

Badudu, J.S. dan Zain, Sutan Mohammad. (2006). Kamus Umum Bahasa. Indonesia. Jakarta: Pustaka Sinar Harapan.

Bahar, Aswandi. (2005). Dasar - Dasar Kependidikan. Jakarta: Departemen Pendidikan dan Kebudayaan.

Bigge, Morris L. (2002) Learning Theories for Teachers. New York: Harper and Row.

Depdikbud. (1996). Bahan Penataran P4 Bagi Siswa Untuk Siswa SLTA. Jakarta: Depdikbud.

Depdikbud. (2003). Kamus Besar Bahasa Indonesia. Jakarta: Balai Pustaka.

Durden, William G. (2005). "Rediscovering Self-Relience in Education: The Optimal Match". Phi DeltaKappa, $v 77$.

Durkheim, Emile. (2005). Organisasi Sekolah dan Pengelolaan Kelas. Jakarta: Gunung Agung.

Felder, Richard. (2006). Navigating the Bumpy Road to Student-Cenrtered Instruction. College teaching $v 44$ Spring.

Feriandi, Y. A. (2016). Pengaruh Peran Guru Pendidikan Pancasila dan Kewarganegaraan dan Pola Asuh Orang Tua terhadap Tindakan Moral Siswa (Doctoral dissertation, UNY).

Hadisubrata. (2002). Mengembangkan Kepribadian Anak Balita. Jakarta: BPK Gunung Mulia.

Hamalik, Oemar. (2001). Proses Belajar Mengajar. Jakarta: Bumi Aksara.

House, Daniel J. (2006). "Relationship between Learner Attitude, Prior Achievement, and Performance in a General Education Course". Interntional Journal of Instructional Media v 23 no 3.

Hurlock, Elizabeth B. (1998). Perkembangan Anak (Jilid 1 Edisi keenam). Jakarta: Erlangga.

Imran, Ali. (2003). Pembinaan Guru Indonesia. Jakarta: Pustaka Jaya.

Kartono, Kartini. (2007). Patologi Sosial 2, Kenakalan Remaja. Jakarta: PT. Raja Grafindo Perkasa.

Kemendiknas. (2010) Kamus Besar Bahasa Indonesia. Jakarta: Kemendiknas.

Kemp, Jerrold E. (2004). Proses Perancangan Pengajaran. Alih Bahasa: Asril Marjohan. Bandung: Penerbit ITB, 2004.

Kusuma, Indra. (2006). Pengantar Ilmu pendidikan. Surabaya: Usaha Nasional.

Vol. 10 No. 1, Desember 2017

Madrasah homepage: http://ejournal.uin-malang.ac.id/index.php/madrasah/index 
Luthan, Rusli. (2003). Belajar Keterampilan Motorik. Jakarta: Depdikbud.

Miarso, Yusufhadi. (2004). Menyemai Benih Teknologi Pendidikan. Jakarta: Prenada Media.

Moenir, A.S. (2001). Pendekatan Manusia dan Organisasi terhadap Pembinaan Kepegawaian. Jakarta: Gunung Agung.

Mulyono. (2008). Kesadaran Berbangsa. Bandung: Angkasa.

Mulyoto, G. P., \& Feriandi, Y. A. Pembelajaran nilai-nilai moral pada anak autis. Jurnal Pendidikan Karakter, 7(2).

Nawawi, Hadari. (2005). Organisasi Sekolah dan Pengelolaan Kelas. Jakarta: Gunung Agung.

Prasetya, Joko T. dan Ahmad, Abu. (2007). Strategi Belajar Mengajar. Bandung: Pustaka Setia.

Priyodarmanto, Soegeng. (1999). Disiplin Kiat Menuju Sukses. Jakarta: Abadi.

Sanjaya, Wina. (2006). Strategi Pembelajaran Berorientasi Standar Proses Pendidikan. Jakarta: Kencana.

Schaefer, Charles. (2005). Mendidik dan Mendisiplinkan Anak. Jakarta: Percetakan Baru.

Soeharto. (2006). Administrasi Pendidikan. Malang: UMN.

Sudjana, Nana. (2008). Penilaian Hasil Proses Belajar Mengajar. Bandung: Rosdakarya.

Sugiyono. (2009). Statistik untuk Penelitian. Bandung: Alfabeta.

Sumadijono, T. (2005). Pengajaran Mikro BPK PAP FKIP UNS. Surakarta: UNS Press.

The Liang Gie. (2001). Ensiklopedi Administrasi. Jakarta: Gunung Agung.

Usman, Tulus T. (2004). Peran Disiplin pada Perilaku Siswa dan Prestasi. Jakarta: Grasindo.

Walgito, Bimo. (2004). Pengantar psikologi Umum. Jakarta: Penerbit Andi Offset.

Wursanto, I.G. (2002). Manajemen Kepegawaian 2. Yogyakarta: Kanisius.

Vol. 10 No. 1, Desember 2017

Madrasah homepage: http://ejournal.uin-malang.ac.id/index.php/madrasah/index 